\title{
Conceptual understanding of Newtonian dynamics in a comparative study of computational modeling and video motion analysis
}

\author{
Jannis Weber \\ Department of physics education research, Goethe University Frankfurt, Max-von-Laue-Str. 1, Frankfurt/M, Hessen, Germany \\ Thomas Wilhelm \\ Department of physics education research, Goethe University Frankfurt, Max-von-Laue-Str. 1, Frankfurt/M, Hessen, Germany
}

\begin{abstract}
There are many difficulties for students when it comes to learning the fundamental relationships in Newtonian mechanics, which is supported by manifold research. Even after class the understanding of Newton's laws of motion is often inadequate, which is problematic because classical mechanics is the foundation of many other areas in physics and the natural sciences in general. These problems stem from the fact that students' preconceptions in the field of mechanics are especially diverse and persistent because they are strengthened in everyday life over the course of many years. These preconceptions and the fact that idealized situations are often most prominent in class can lead to a felt incompatibility of everyday life and physics lessons. The computer can be a tool to reduce that gap by discussing complex and authentic motions in class without the need to use difficult mathematics, which can lead to reduction in certain unwanted preconceptions. Two different ways of using the computer in mechanics class, computational modeling and video motion analysis, are discussed in this article. The two methods are compared in a pre-post design study with $\mathrm{N}=267$ students from $11^{\text {th }}$ grade from German high schools in regard to the overall conceptual understanding of Newton's first two laws. The results suggest that both methods can be successful in teaching the basic concepts of Newtonian dynamics and no differences can be seen in the overall scores for conceptual understanding. Furthermore, it seems that computational modeling performs better in items regarding Newton's first law due to a comparatively greater reduction of a specific preconception, which is further discussed in the article.
\end{abstract}

2021 PERC Proceedings edited by Bennett, Frank, and Vieyra; Peer-reviewed, doi.org/10.1119/perc.2021.pr.Weber

Published by the American Association of Physics Teachers under a Creative Commons Attribution 4.0 license.

Further distribution must maintain the cover page and attribution to the article's authors. 


\section{INTRODUCTION}

There are many preconceptions in Newtonian mechanics that are especially persistent, even after class [1]. One possible explanation is that the motions that are being discussed in class are similar to motions from the everyday life of students. Therefore, the preconceptions are established over a long time.

A well-known example is that students often think that a constant force in the direction of the motion is necessary for an object to move at all [2]. This preconception stems from motions in everyday life, such as riding a bike, where one must exert a constant force to move with a constant speed. Without a specific discussion of friction, Newton's laws often cannot be identified by students in everyday life [3] and thus, the desired conceptions are much more likely to be rejected. Nonetheless, pure phenomena are the norm in physics class that ignore "disturbing" influences [4], partly because of the mathematical complexity of e. g. velocitydependent forces, like air friction.

The computer can be a tool to help reduce said complexity in different ways. It is possible to use the computer to model a physical system. The arising differential equations can be solved numerically while the user can focus on the underlying physics. Though there are different ways to use computational modeling (CM), the common denominator is that the user must think about the acting forces (and initial conditions) and, depending on the software, also the relationships between the relevant quantities, whereas the calculation and presentation of the data is done by the software. A different approach is to use the computer as a tool to measure and collect data and to present that data. One example for that is video motion analysis (VMA) software that frees the user of the complex mathematics and therefore allows a discussion of authentic and realistic problems in the field of mechanics as well. We argue that these methods allow an improvement in conceptual understanding and a reduction in unwanted preconceptions in students because of the ability to focus on authentic motions while reducing mathematical complexity.

\section{THEORY}

\section{A. Computational Modelling}

Computational modeling in general means the construction of a network of physical concepts and relationships on a computer with which the behavior of a physical system can be described and predicted [5]. In general, computational physics is seen as the third pillar of physics (and science in general) alongside experimental physics and theoretical physics by many [e. g. 6-8]. Thus, the use of computational modeling in schools can be justified by its importance for the scientific process. Additionally, it can be used to improve the conceptual understanding of important concepts [9]. Computational modeling is being used in physics education since the 1980s [10]. Since then, the available software has changed greatly which also led to more possibilities in the way the software is being used.

Early on, computational modeling consisted mostly of the use of programming languages (see [10] for a historic overview). Teachers and researchers also explored the use of spreadsheet software for that purpose. Another way to use $\mathrm{CM}$ to teach physics is graphical modeling software, that enables the user to create the network of physical quantities to visualize the relationships and later quantify them. Additionally, there are equation-based modeling programs that aim to be easier to use. It is also possible to use software that show the motion of the modeled object in an animation - additional to the graphs of the other mentioned programs such as VPython, which is most common in the US.

So far, studies have shown that using VPython in beginner physics classes of universities can lead to a more interesting and student-centric class that also increases the gain in conceptual understanding compared to the classical approach [9]. It is more difficult to use programming languages to model physical systems in schools though [11].

Using graphical modeling programs in schools, researchers showed a small improvement in conceptual understanding over the classical approach [12-13] Other hypotheses, such as an improvement in systemic thinking due to the nature of the modeling software could not be confirmed [12,14]. Some of the shortcomings were explained with difficulties related to the software [15]. Though it is also possible to use spreadsheet software to model movements [16-18], there are programs specifically built for the use of computational modeling in mechanics classes in school, like "Newton-II" [19]. These enable students to easily use the software themselves without the need to learn a programming language first. "Newton-II" does not put an emphasis on the graphical representation of the relationships between the physical quantities. Students simply use equations to model the behavior of an object and can easily compare the results to real data from an experiment in the same graph. The main part of the modeling process is to formulate the acting forces and the relationships between forces and acceleration, whereas the relationships between acceleration, velocity, and location are implemented in the software. We are not aware of any empirical data regarding the efficacy of programs such as "Newton-II" in Newtonian mechanics in schools.

\section{B. Video motion analysis}

Video motion analysis is a contactless way to measure 2D-motions. It makes use of the fact that a video contains information about the location of an object and the time. Though it is possible to use VMA manually, dedicated software enables measuring the location at different times and calculates the velocity and acceleration of the object automatically. Additionally, it offers different ways to 
display the data, such as graphs, arrows, stroboscopic images etc. For many years, video motion analysis has been used in physics courses [20]. Today it is used regularly on laptops, tablets, and smartphones, while each method has its advantages depending on the situation and the desired goal.

The literature regarding the success of video motion analysis is overwhelmingly positive. Researchers found that, among others, it improves the understanding of graphs [21], the conceptual understanding of a braking motion [22] and the motivation and curiosity regarding the subject [23]. Additionally, it can improve the conceptual understanding of demanding tasks in kinematics more than traditional approaches [24], and the use of multiple representations has a positive effect on the learning gain [25]. In general, most of the findings concern the area of kinematics. Much less is known about the use of VMA in schools in dynamics. Thus, in this study a software package called "measure dynamics" [26], which is similar to the software "Tracker" [27], is used on laptops to improve students' conceptual understanding of Newtons first two laws of motion.

\section{Comparison}

The two mentioned ways to use the computer in physics class in the field of dynamics are quite different. Computational modeling on the one hand is about modeling a physical system. The process starts with theoretical considerations about forces, whereas the acceleration is calculated from the sum of all acting forces. Similarly, the velocity is derived from the acceleration and the location from the velocity. Video motion analysis on the other hand starts by measuring the location of an object at different times and calculates the velocity and acceleration. The sum of all acting forces can then be derived from the acceleration of the object. The two methods therefore differ in their direction of argumentation between forces and motion. The direction of that argumentation in general is known to make a difference for students regarding the difficulty of an item and the activated preconception [28]. It is not known though whether one of the two methods discussed above increases the probability of a correct response in items that use one direction of reasoning more than the other, i.e., whether computational modeling improves the ability to argue from forces to motion more, whereas video motion analysis improves the ability to argue from motion to forces more.

Although there is not much data about the efficacy of using VMA in the field of dynamics, it is in general more established in (German) schools and the results that exist are overwhelmingly positive. CM is less established and software that has been utilized in the past has been problematic, which is why it is reasonable to investigate the use of supposedly simpler modeling programs.

\section{GOAL OF THE PRESENTED STUDY}

The presented reasoning leads to the first research question: Does the use of a user-friendly computational modeling software lead to an increase in conceptual understanding in Newtonian dynamics? A similar research question is relevant for video motion analysis, which has already been shown to be successful in kinematics: Does the use of video motion analysis lead to an increase in conceptual understanding in Newtonian dynamics? The two methods use different directions of argumentation. Its implications for students conceptual understanding are unclear: Does each method improve the success in the direction of arguing between forces and motion that is associated to it more than the other? Since many difficulties in Newtonian dynamics are caused by students' preconceptions, a comparative analysis between the two methods with regard to the most prominent preconceptions is of interest: Is one of the two methods superior in reducing unwanted preconceptions? The study aims to answer these research questions.

\section{DESIGN}

To answer the research questions a comparative pretestposttest intervention study was designed. One intervention uses computational modeling with "Newton-II" to teach Newton's first two laws of motion, whereas the other intervention uses video motion analysis with "measure dynamics". Apart from the software utilized and the different approaches associated with them, the interventions are similar. The participants are students from $11^{\text {th }}$ grade of German high schools that visit the university to take part in the 4-hour long intervention after they discussed Newton's laws of motion in school. The pretest is done prior to the visit in class whereas the posttest takes place immediately after the intervention.

\section{A. Test}

The test that is used in this study is partly based on the Force Concept Inventory (FCI) [29] but was created for this study to have reliable subscales, that can differentiate between the directions of argumentation between forces and motion. For this purpose, some of the items of the FCI were used unchanged (three), some were altered or extended (six) and others were newly created (three). The remaining three items are from [30-32].

TABLE I. Different scales and their reliability in the test for conceptual understanding.

\begin{tabular}{lccc}
\hline \multicolumn{1}{c}{ Scale } & $\mathbf{N}^{\circ}$ of Items & $\boldsymbol{\alpha}_{\boldsymbol{C}}$ & Item Sources \\
\hline $1^{\text {st }}$ Newton & 4 & 0.75 & {$[29]$} \\
Force to Motion & 6 & 0.70 & {$[29]$} \\
Motion to Force & 5 & 0.74 & {$[29-32]$} \\
\hline \hline
\end{tabular}




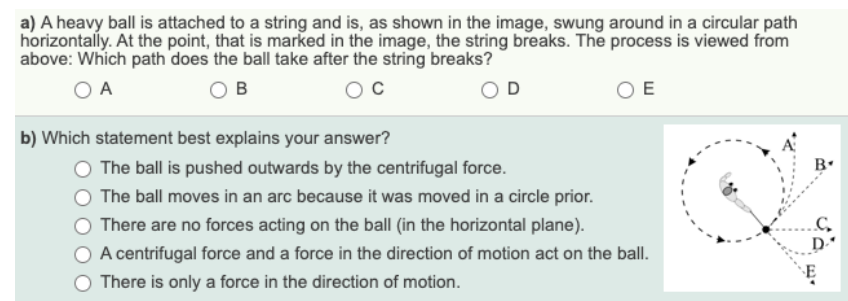

FIG. 1: Translation of an item from the test (changed layout).

The conceptual understanding part consists of three content areas - Newton's first law, forces to motion argumentation and motion to forces argumentation. These scales were found in a pilot study with $\mathrm{N}=85$ participants, which also showed its reliability (Table 1 ). The validity of the items was tested in an expert survey with German secondary school teachers. By adding a second tier, where students must give a reason for their answer, more information about a preconception is revealed. For example, in the item above (Fig. 1), which is from the FCI originally, students must choose the path of the object and then give an explanation for their answer. Figure 2 gives another example of an item from the test.

Additionally, other concepts like interest, self-efficacy, cognitive load, and other affective variables were included in the test, partly to check for differences between the groups prior to the intervention. Furthermore, a kinematic concept, i.e., the understanding of acceleration graphs was tested.

\section{B. Interventions}

The interventions consist of four experiments that were chosen based on the known preconceptions. These divide the interventions into four phases. In each phase, the experiment is done in front of class. Then, students work in groups of two on one laptop and have a workbook each, where questions must be answered about the model/analysis. At the end of each phase there is a discussion of the results. An exception is the first experiment, where everything related to the software is shown by the teacher while the students copy that on their laptops to get to know the program.

The four mentioned experiments are a falling cone that reaches terminal velocity due to air friction, a wagon that is accelerated horizontally by a falling weight that reaches the ground after half of the way, a projectile motion (without and with air friction) and a circular motion with constant speed, where the centripetal force is switched off after a while. One of the main objectives is to associate a constant velocity with a zero net force and vice versa, as this is one of the most common problems students have regarding Newton's laws.

The group that uses computational modeling always discusses the acting forces, tries to model them, and evaluates the model. They repeat the process until satisfied with the result. Then, they import the real data from the experiment that is prepared and evaluate the model again. As soon as the model is seen as adequate, some questions from the workbook about the motion must be answered.

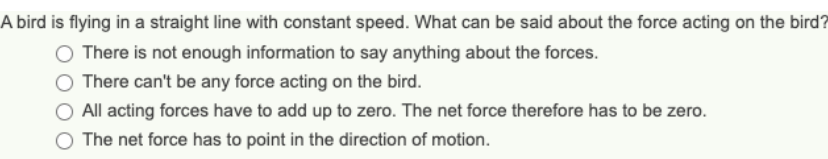

FIG. 2: English translation of an item from the test.

The group that uses video motion analysis analyzes the video, that is already prepared and examines the motion in different ways, using arrows for acceleration and velocity, different graphs, and stroboscopic images. They mostly conclude the sum of all acting forces by analyzing the acceleration. The questions in both groups regarding the physical quantities are similar, as far as this is possible.

\section{Sample}

In total $\mathrm{N}=267$ German $11^{\text {th }}$ grade high school students took part in the study after they discussed Newton's laws in school. They were assigned to the groups quasi-randomized, because each class was randomly assigned to one intervention as a whole. There were no differences in all the measured covariates prior to the intervention and the groups can therefore be seen as sufficiently similar in the relevant variables (interest, self-efficacy, grades etc.).

\section{RESULTS}

As discussed in section IV A., the test has 15 items in the field of dynamics. The effect of the interventions in both groups were analyzed with a total of $\mathrm{N}=139$ participants in the group of computational modeling and $\mathrm{N}=128$ in the group of video motion analysis (Fig 3).

Because the data is sufficiently normally distributed a paired t-test was done to test for differences in the means in pretest and posttest. Both groups had a significantly higher $(\mathrm{p}<0.001)$ score in the posttest than in the pretest with large effect sizes [33] of $d=1.01$ (95\%-CI [0.85; 1.19]) in the CM group and $\mathrm{d}=1.13[0.94 ; 1.36]$ in the VMA group. It seems that an intervention that is designed based on the known preconception is effective in improving the conceptual understanding in both groups. This is especially promising since the interventions took place after the lesson in school. No difference between the groups in the overall learning gain were observed $(F(1,263)=0.13, p=0.72$, Fig. 4).

Scores in pretest and posttest in both groups

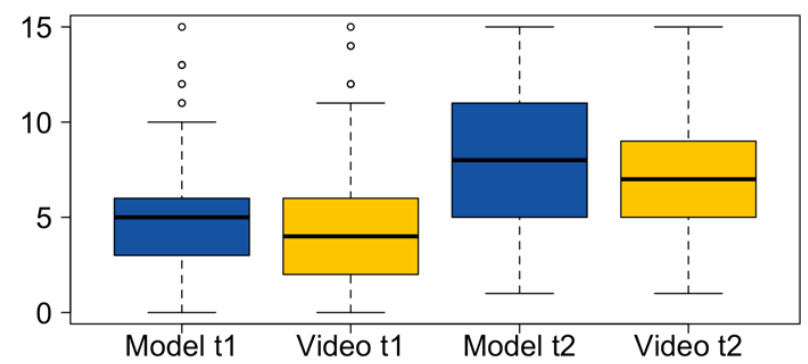

FIG. 3: Box and whiskers plots (standard characteristics) of the scores in the pretest (t1) and posttest (t2) in both groups. 


\section{Conceptual Understanding}

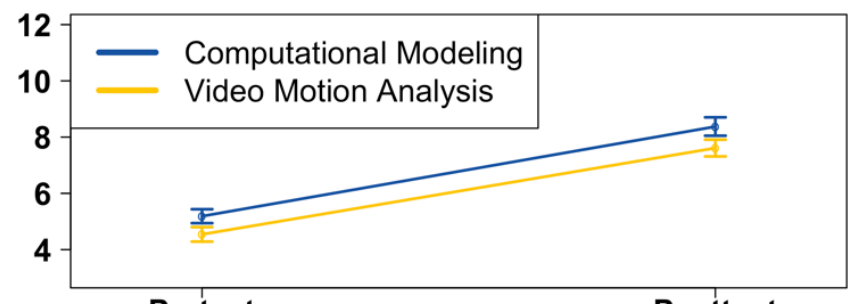

\section{Pretest}

Posttest

FIG. 4: Average total scores in both groups in the items regarding dynamics in pretest and posttest with standard error.

The test, however, allows a more detailed analysis of the different content areas since the reliability of the subscales were shown in the pilot study (see A). It was hypothesized that CM could, because of its inherent logic, benefit arguing about the motion of an object while knowing the forces, while the opposite way of argumentation would benefit the VMA group. To test that hypothesis, these two concepts were compared between the groups. Performing an ANCOVA, no differences between the groups were observed $(F(1,264)=0.12, p=0.73$ and $F(1,264)=0.00083$, $\mathrm{p}=0.98)$ in the different directions of argumentation. It seems that the primary argumentation of the used method does not influence the scores in the respective categories. There is, however, a difference in the learning gain in the area of Newton's first law $\left(\mathrm{F}(1,264)=4.19, \mathrm{p}<0.05, \eta_{g}^{2}=\right.$ 0.02 ) with a small effect size (Fig. 5).

Since the items included in the category "Newton's First Law" ask for the forces while an object is moving with a constant velocity in different contexts, it might be surprising at first, that the $\mathrm{CM}$ cohort performs better after the intervention than the other group. This again shows the direction of argumentation in the intervention does not play an important role in the outcome. It can, however, be argued that the improvement in this category can be explained by a reduction in the preconception, that a moving object must experience a force in the direction of motion [28], since this preconception is widely present in students and would produce a wrong answer in these items. Students would choose a net force in the direction of motion if this preconception was activated.

Newton's First Law

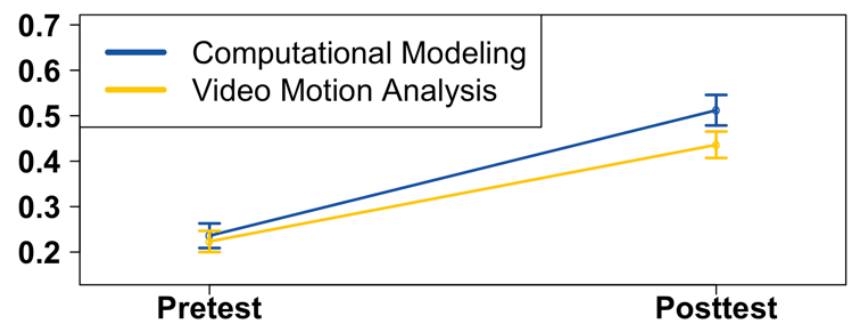

FIG. 5: Average relative scores in both groups in the scale "Newton's first law" in pretest and posttest with standard error.
'A force in the direction of motion is necessary'

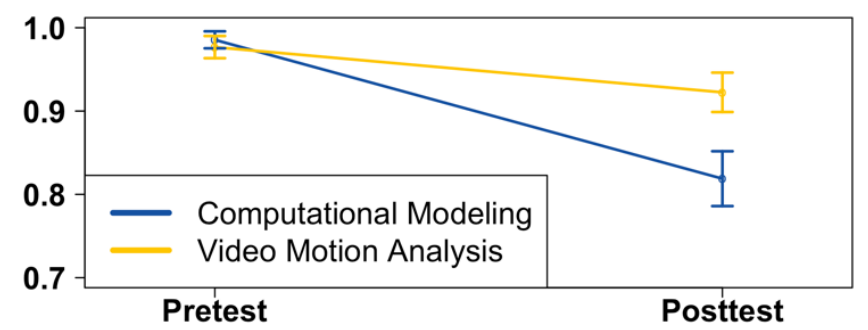

FIG. 6: Relative number of students that answer as if the preconception that a force in the direction of motion is necessary was activated at least once in pre- and posttest with standard error.

It is possible to analyze the wrong answers of the participating students in the whole test to get insight in the underlying preconceptions that lead to a certain answer (Fig. $6)$. The discussed preconception is indeed reduced further in the group of $\mathrm{CM}$ in the posttest $\left(\chi^{2}(1, N=267)=5.4\right.$, $\mathrm{p}<0.05)$, which leads to a greater improvement in the items regarding Newton's first law. A possible reason for this further decrease in the $\mathrm{CM}$ cohort could be that students are reflecting on the relationship between forces and motion more deeply due to the active modeling process. Still, about $80 \%$ of participants in the group of CM and over $90 \%$ in the group of VMA answer in a way that the mentioned preconception could be the reason at least once in the test even after the interventions. That shows how prevalent preconceptions are, and also how important it is to consider them, since the extent to which unwanted preconceptions are activated in students is relevant for their conceptual understanding, which in this case varies by treatment.

\section{DISCUSSION}

We argue that both investigated methods are beneficial to teach the basic relations in Newtonian dynamics. There are not many differences regarding the results between the two methods. Due to the importance of computational modeling for science in general, and the fact that software such as "Newton-II" seems to be easy enough to use for students without a lengthy introduction, a case for an increased use of $\mathrm{CM}$ in schools can be made, especially because it decreased one of the most common preconceptions further than video motion analysis, which can be explained by the active modeling process. VMA on the other hand can be used not only to teach kinematics but also dynamics. It would be beneficial to use the software during the whole year of mechanics lessons more than once since it is known to be beneficial in kinematics and the students can get used to the software making its use more efficient over time. Contrary to students' preconceptions, the inherent direction of argumentation of the two methods does not influence their performance. 
[1] H. Schecker, T. Wilhelm, M. Hopf, and R. Duit, Schülervorstellungen und Physikunterricht. Ein Lehrbuch für Studium, Referendariat und Unterrichtspraxis (Springer Spektrum, Berlin, 2018).

[2] I. Halloun, and D. Hestenes, Common sense concepts about motion, Am. J. Phys. 53, 1056 (1985).

[3] A. DiSessa, Unlearning Aristotelian physics: a study of knowledge-based learning, Cognitive Science 6, 37 (1982).

[4] T. Wilhelm, Konzeption und Evaluation eines Kinematik/Dynamik-Lehrgangs zur Veränderung von Schülervorstellungen mit Hilfe dynamisch ikonischer Repräsentationen und graphischer Modellbildung (LogosVerlag, Berlin, 2005).

[5] H. Schecker, Physik modellieren. Grafikorientierte Modellbildungssysteme im Physikunterricht (Klett, Stuttgart, 1998).

[6] M. Riedel, A. Streit, F. Wolf, T. Lippert, and D. Kranzlmüller, Classification of Different Approaches for e-Science Applications in Next Generation Computing Infrastructures, in Proceedings of the IEEE Fourth International Conference on eScience, USA, 2008, edited by IEEE Computer Society (NW Washington, DC) p. 201 , https://doi.org/10.1109/eScience.2008.56

[7] M. Obsniuk, P. Irving, and M. Caballero, A Case Study: Novel Group Interactions through Introductory Computational Physics, arXiv:1511.05457 (2015).

[8] R. Landau, Computational Physics Education; why, what and how, Comput. Phys. Commun. 177, 191 (2007).

[9] P. Irving, M. Obsniuk, and M. Caballero, P3: a practice focused learning environment, Eur. J. Phys. 38, 055701 (2017).

[10] J. Weber and T. Wilhelm, The benefit of computational modelling in physics teaching: A historical overview, Eur. J. Phys., 41, 034003 (2020).

[11] M. Caballero, J. Burk, J. Aiken, B. Thoms, S. Douglas, E. Scanlon, and M. Schatz, Integrating numerical computation into the modelling instruction curriculum, Phys. Teach. 52, 38 (2014).

[12] H. Schecker, E. Klieme, H. Niedderer, J. Ebach, and J. Gerdes, Physiklernen mit Modellbildungssystemen. Förderung physikalischer Kompetenz und systemischen Denkens durch computergestützte Modellbildungssysteme, Abschlussbericht (Report) zum DFG-Projekt, Institut für Didaktik der Physik an der Universität Bremen und Max-Planck-Institut für Bildungsforschung Berlin, 1999 (unpublished), http://www.idn.uni-bremen.de/pubs/DFG_PMS_Ab.pdf

[13] H. Schecker, Physiklernen mit Modellbildungssystemen-Forschungskonzeptionen, in Proceedings of the Conference Zur Didaktik der Physik und Chemie, Probleme und Perspektiven, Vorträge auf der Tagung für Didaktik der Physik/Chemie, Potsdam, 1997, edited by H. Behrendt (University of Potsdam, 1998), p. 230.

[14] E. Klieme and U. Maichle, Modellbildung Und Simulation im Unterricht der Sekundarstufe I-Auswertung von Unterrichtsversuchen mit dem Modellbildungssystem MODUS (Institut für Bildungsforschung, Bonn, 1994).

[15] F. Sander, Verbindung von Theorie und Experiment im physikalischen Praktikum. Eine empirische Untersuchung zum handlungsbezogenen Vorverständnis und dem Einsatz grafikorientierter Modellbildung im Praktikum Studien zum Physiklernen (Logos-Verlag, Berlin, 2000).

[16] J. Benacka, Projectile general motion in a vacuum and a spreadsheet simulation, Phys. Educ. 50, 58 (2015).

[17] J. Benacka, Spreadsheet application showing the proper elevation angle, points of shot and impact of a projectile, Phys. Educ. 50, 342 (2015).

[18] J. Benacka, Numerical modelling with spreadsheets as a means to promote STEM to high school students, Eurasia Journal of Mathematics, Science \& Technology Education 12, 947 (2016).

[19] https://did-apps.physik.uni-wuerzburg.de/Newton-II

[20] P. Laws. and H. Pfister, Using digital video analysis in introductory mechanics projects, Phys. Teach. 36, 282 (1998).

[21] R. Beichner, The impact of video motion analysis on kinematics graph interpretation skills, Am. J. Phys. 64, 1272 (1996).

[22] P. Hockicko, B. Trpišová, and J. Ondruš, Correcting students' misconceptions about automobile braking distances and video analysis using interactive program tracker, Journal of Science Education and Technology, 23, 763 (2014).

[23] D. Zollman and L. Escalada, Applications of interactive digital video in a physics classroom, Journal of Educational Multimedia and Hypermedia 5, 73 (1996).

[24] A. Becker, P. Klein, A. Gößling, and J. Kuhn, Förderung von Konzeptverständnis und Repräsentationskompetenz durch Tablet-PC-gestützte Videoanalyse - Empirische Untersuchung der Lernwirksamkeit eines digitalen Lernwerkzeugs im Mechanikunterricht der Sekundarstufe 2, Zeitschrift für Didaktik der Naturwissenschaften 25, 1 (2019).

[25] K. Hochberg, S. Becker, M. Louis, P. Klein, and J. Kuhn, Using Smartphones as Experimental Tools-a Follow-up: Cognitive Effects by Video Analysis and Reduction of Cognitive Load by Multiple Representations, Sci. Educ. Technol. 29, 303 (2020).

[26] https://www.phywe.de/sensoren-software/mess-softwareapps/software-measure-dynamics-einzellizenz/a-2259/

[27] https://physlets.org/tracker/

[28] A. Just, C. von Aufschnaiter, and A. Vorholzer, Effects of conceptual and contextual task characteristics on students' activation of mechanics conceptions, Eur. J. Phys., 42, 025702 (2021).

[29] D. Hestenes, M. Wells, and G. Swackhamer, Force Concept Inventory, Phys. Teach. 30, 141 (1992).

[30] T. Wilhelm, Vektorverständnis und vektorielles Kinematikverständnis von Studienanfängern, in Proceedings of the Conference Didaktik der Physik, Regensburg, 2007, edited by V. Nordmeier, A. Oberländer, and H. Grötzebauch (University of Regensburg, Regensburg, 2007).

[31] S. Flores, S. Kanim, and C. Kautz, Student use of vectors in introductory mechanics, Am. J. Phys. 72, 460 (2004).

[32] J. Warren, Understanding Force (John Murray, London, 1979).

[33] J. Bortz and N. Döring, Forschungsmethoden und Evaluation - für Human- und Sozialwissenschaftler (Springer, Heidelberg, 2006), Vol. 4., p. 609. 